\title{
SENSITIVITY STUDY OF INPUT PARAMETERS FOR SEEPAGE FLOW SIMULATIONS USING PARALLEL COMPUTERS*
}

\author{
FRED T. TRACY ${ }^{\dagger}$ LUCAS A. WALSHIRE $\ddagger$ AND MAUREEN K. CORCORAN $§$
}

\begin{abstract}
This paper describes a comprehensive sensitivity study that was performed using high performance parallel computers to understand the importance of input parameters to a transient partially saturated finite element seepage analysis for a levee with separate soil layers of sand, silty sand, and clay. Seepage flow in this paper refers to the type of flow of water that occurred through the failed levees in New Orleans, Louisiana, USA, as a result of Hurricane Katrina. The input parameters tested were saturated hydraulic conductivity, volumetric compressibility, residual moisture content, saturated moisture content, and two van Genuchten unsaturated flow parameters. The output data compiled to show the sensitivity of the input parameters were the simulation times (days) to achieve $25 \%, 50 \%$, and $75 \%$ of the steady-state values of pore pressure at the toe of the levee beneath its blanket, flow rate through the landside flux section, and the level of saturation in the levee. The use of high performance parallel computers enabled the running of thousands of scenarios using different values for the input variables. A sensitivity investigation of this magnitude has not been previously performed.

The results of this investigation indicated that the more sensitive soil parameters were the saturated hydraulic conductivity and the volumetric compressibility. The unsaturated van Genuchten parameters of the landside blanket had a larger than anticipated impact on the duration of time to achieve steady state. This practical example is an excellent success story for high performance computing in that running a given simulation for a couple of hours on thousands of processors in parallel replaced over a year's work using a PC.
\end{abstract}

Key words: high performance computing, sensitivity analysis, finite element method, seepage flow modeling

AMS subject classifications. 35J66, 65Y05, 76S05

1. Introduction. Historically, the majority of practicing engineers have used two-dimensional (2-D) steady state analyses to design and analyze levees. Finite element programs such as SEEP2D [1,2] in the Groundwater Modeling System (GMS) [3,4] and SEEP/W [5] with excellent graphical user interfaces have greatly aided these design and analysis processes. However, using only steady-state analyses leads to the most conservative and therefore, the most expensive design. With the ability to now do a transient seepage analysis on a computer, key questions are when should a design be based on a transient analysis instead of a steady-state analysis, what soil parameters are important in the transient analysis, and how reliable are the transient simulation results.

One traditional analytical tool used in determining the relative importance of the various input parameters is a sensitivity study. Some sensitivity analyses have been historically too compute-intensive to perform. However, with the availability of high performance, parallel computing, thousands of scenarios can be run at once, allowing for the testing of a greater number of input parameters than was previously possible.

The purpose of this research was to perform a comprehensive sensitivity study of input soil parameters needed for a transient finite element seepage analysis as measured by the response of key output variables. A generic levee common to the southeastern United States was selected for the analysis. To perform the analysis, a parallel program was created such that from a set of data describing the levee cross section, a finite element mesh was generated, initial and boundary conditions were applied, both steady-state and transient seepage analyses were performed, and key data were stored for future analysis. This was all done in the context of parallel computing where thousands of scenarios could be computed simultaneously. A feature of the groundwater modeling program used in the study is that the time needed to achieve a certain percentage of the steady-state value of a given output variable can be computed and stored for future analysis. This is possible because a steady-state solution is computed before the transient solution is performed. This modified parallel groundwater modeling program made this research possible. Because of all the obstacles, very few sensitivity studies of this magnitude have been completed with no known studies performed on this magnitude for transient seepage.

\footnotetext{
${ }^{*}$ This work was supported in part by a grant of computer time from the Department of Defense High Performance Computing Modernization Program (HPCMP).

†Information Technology Laboratory, Engineer Research and Development Center (ERDC), Vicksburg, MS, USA.

${ }^{\ddagger}$ Geotechnical and Structures Laboratory (GSL), ERDC, Vicksburg, MS, USA.

$\S$ GSL, ERDC, Vicksburg, MS, USA.
} 
2. Measuring sensitivity. There are many ways to measure sensitivity of an output variable to an input parameter, and an excellent description of them is given in [6]. This information will not be repeated here but rather some key methods of doing sensitivity studies for numerically intensive applications are highlighted. The method of slopes and the method of ranges were used in this investigation.

2.1. Method of slopes. Changing only one input parameter while holding all the others constant and measuring the output to obtain the slope of the output variable versus the varied input parameter curve is the simplest way of doing a sensitivity analysis [6]. The slope, $m$, for a given output value $(Y)$ versus input parameter $(X)$ curve is simply the partial derivative,

$$
m=\frac{\partial Y}{\partial X}
$$

This curve can be determined by using different values of $X$, running the transient seepage program, and then recording the resulting $Y$ output values. Because this slope was determined numerically, it was approximated as follows:

$$
m \approx \frac{\Delta Y}{\Delta X}
$$

where $\Delta X$ is a small increment of input parameter, and $\Delta Y$ is the resulting small change in the output value.

Only one type of output parameter was considered in this study, but several input parameters varying over several orders of magnitude were considered. Therefore, a sensitivity coefficient, $s_{m}$, fashioned after [7] was implemented. Defining $Y(X)$ as the output, $Y$, as a function of the input parameter, $X, s_{m}$ is

$$
s_{m}=\frac{Y\left(X+\frac{p}{100} X\right)-Y(X)}{p}
$$

where $p$ is a percentage of a given input parameter. Because of the highly nonlinear nature of the governing partial differential equation where repeated Picard or Newton iterations [8] are needed, a value of $p=10$ was selected. The sensitivity coefficient, $s_{m}$, can be computed for different values of the input parameters to obtain an overall view of the nonlinear behavior.

2.2. Method of ranges. The method of ranges is useful when the output can be sampled over the entire range of the respective input parameters. This method compares how much the output variable changes when the different input parameters are varied. A sensitivity coefficient based on ranges is now defined, which is an extension of previous work [9]. The case where there are $i=1,2,3, \ldots, M$ scenarios of the $j=1,2,3, \ldots, N$ input parameters was considered. Defining $K_{j}$ as the number of different values of the $j^{\text {th }}$ input parameter, $M$ in this research becomes

$$
M=K_{1} K_{2} K_{3} \cdots K_{N}=\prod_{j=1}^{N} K_{j}
$$

Eq. 2.4 is rearranged to isolate the $j^{\text {th }}$ input parameter as follows:

$$
M=\left(\prod_{i=1, i \neq j}^{N} K_{i}\right) K_{j}=M_{j} K_{j}
$$

where $M_{j}$ is the number of combinations of all the input parameters except the $j^{\text {th }}$ one. For each of these $m=1,2,3, \ldots, M_{j}$ combinations, the results of varying the $j^{\text {th }}$ input parameter over its range while holding the other input parameters constant are used to define a sensitivity coefficient based on the range of the output values. The sensitivity coefficient for this $m^{\text {th }}$ scenario while changing only the $j^{t h}$ input parameter is defined as follows:

$$
s_{r m}^{j}=\frac{\left(Y_{\max }\right)_{m j}-\left(Y_{\min }\right)_{m j}}{Y_{\max }-Y_{\min }}
$$


where

$\left(Y_{\text {min }}\right)_{m j}=$ minimum value of output, $Y$, when varying the $j^{\text {th }}$ input parameter and holding the others constant for the $m^{\text {th }}$ combination

$\left(Y_{\max }\right)_{m j}=$ maximum value of output, $Y$, when varying the $j^{\text {th }}$ input parameter and holding the others constant for the $m^{\text {th }}$ combination

$Y_{\min }=$ overall minimum value of the output variable, $Y$

$Y_{\max }=$ overall maximum value of the output variable, $Y$

The overall sensitivity coefficient for the $j^{\text {th }}$ input parameter is computed by taking the maximum value of the $s_{r m}^{j}$ values over the $M_{j}$ combinations. That is,

$$
s_{r}^{j}=\max _{m=1}^{M_{j}}\left(s_{r m}^{j}\right)
$$

2.3. Statistical methods. There are many statistical methods for calculating sensitivity. One of the simplest methods that uses simple correlation coefficients was derived from Monte Carlo simulations [10]. Here, Pearson's product moment correlation coefficient [11] was employed. The case that is now considered is where $M$ output values are computed from $M$ values of an input parameter, $X$. Pearson's product moment correlation coefficient is given by

$$
\begin{gathered}
r=\frac{\sum_{i=1}^{M}\left(X_{i}-\bar{X}\right)\left(Y_{i}-\bar{Y}\right)}{\sqrt{\left[\sum_{i=1}^{M}\left(X_{i}-\bar{X}\right)^{2}\right]\left[\sum_{i=1}^{M}\left(Y_{i}-\bar{Y}\right)^{2}\right]}} \\
\bar{X}=\frac{1}{M} \sum_{i=1}^{M} X_{i} \\
\bar{Y}=\frac{1}{M} \sum_{i=1}^{M} Y_{i}
\end{gathered}
$$

The larger the $r$ value, the stronger the reaction of the output to the input [12]. This works best when the relationship between input parameter and output variable is linear. However, the application presented in this paper is highly nonlinear.

3. Levee. Eqs. 2.3 and 2.7 were applied to a generic levee. The geometry, material properties, initial conditions, boundary conditions, and hydrograph of the river are provided in the following subsections. Detail is provided for those practicing geotechnical engineers who find such information important.

3.1. Generic levee cross section. A 2-D finite element model of a generic levee cross section representative of the southeastern United States is shown in Fig. 3.1 (this section is further described in [13]). This model was used to perform computations and to do the sensitivity study described in this paper.

3.2. Riverside and landside water elevation. The initial river elevation was set to $-5 \mathrm{ft}$. An initial water elevation below the ground surface is the most interesting case because the water must rise through two of the three soil layers as it reaches its maximum height. The river elevation advanced at $2 \mathrm{ft} /$ day until it reached $17.5 \mathrm{ft}$ where it was held constant indefinitely. This is illustrated in the hydrograph shown in Fig. 3.2 where the time for the hydrograph is plotted for only 30 days but extends indefinitely.

4. Input parameters selected for the sensitivity study. Table 4.1 gives the input parameters and respective descriptions selected for variation in the sensitivity study. The first case considered was a homogeneous levee and foundation section where the levee and foundation are all assigned one set of values. In the next case, different material properties were assigned to three layers: levee, blanket, and aquifer. With reference to Fig. 3.1, the levee material would be a lean clay, the blanket would be the silty sand, and the aquifer would be the clean sand. The geometry of the cross section remained constant throughout the study. 


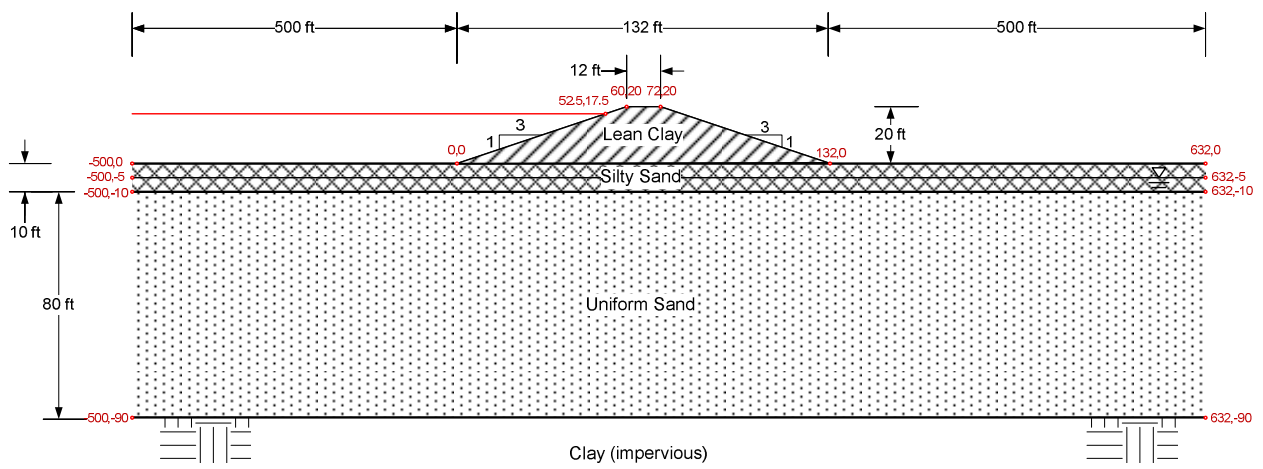

Fig. 3.1: Generic levee cross section showing three separate layers of sand, silty sand, and clay.

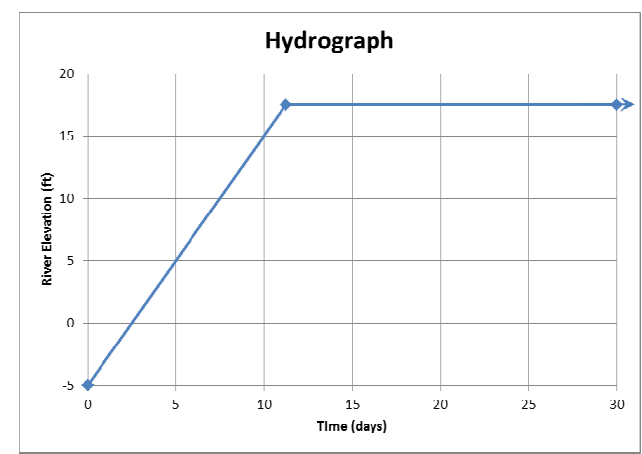

Fig. 3.2: Hydrograph that starts at $-5 \mathrm{ft}$ and then goes up $2 \mathrm{ft} /$ day until $17.5 \mathrm{ft}$ is reached and then remains constant indefinitely.

Table 4.1: Parameters used in the levee system study.

\begin{tabular}{|c|c|}
\hline Name & Symbol \\
\hline Saturated hydraulic conductivity (ft/day) & $k_{s}$ \\
Residual volumetric water content (unitless) & $\theta_{r}$ \\
Saturated volumetric water content (unitless) & $\theta_{s}$ \\
First van Genuchten parameter (1/ft) & $\alpha$ \\
Second van Genuchten parameter (unitless) & $n$ \\
Volumetric compressibility(1/psf) & $m_{v}$ \\
\hline
\end{tabular}

5. Output variables selected for the sensitivity study. The output variables selected for this research are the simulation time in days to achieve $25 \%, 50 \%$, and $75 \%$ of the steady-state values of the following three quantities:

- The pore pressure (psf) at the toe of the levee beneath the blanket (coordinates 132, -10 in Fig. 3.1).

- The flow rate per unit length $\left(\mathrm{ft}^{3} / \mathrm{day} / \mathrm{ft}\right)$ of water leaving the flux section, $(132,0)$ to $(632,0)$ to $(632$, -90) in Fig. 3.1.

- Levee saturation coefficient.

The levee saturation coefficient is defined as

$$
S_{L}=\frac{\iint_{A} \theta(x, y, t) d x d y-\iint_{A} \theta(x, y, 0) d x d y}{\iint_{A} \theta(x, y, \infty) d x d y-\iint_{A} \theta(x, y, 0) d x d y}
$$


Table 6.1: Values of input parameters used in the homogeneous case.

\begin{tabular}{|c|c|}
\hline Parameter & Value \\
\hline$\theta_{r}$ & 0.034 \\
$\theta_{s}$ & 0.46 \\
$\alpha$ & $0.488 \mathrm{ft}^{-1}$ \\
$\mathrm{n}$ & 1.37 \\
$m_{v}$ & $1.0 \times 10^{-5} \mathrm{psf}^{-1}$ \\
\hline
\end{tabular}

where
$A=$ area of the levee
$\theta(x, y, t)=$ volumetric moisture content of an $(x, y)$ point in the levee at time, $t$
$\theta(x, y, 0)=$ volumetric moisture content of an $(x, y)$ point in the levee at $t=0$
$\theta(x, y, \infty)=$ volumetric moisture content of an $(x, y)$ point in the levee at steady state

It is important to note that $0 \leq S_{L} \leq 1$ since $S_{L}=0$ at initial conditions, and $S_{L}=1$ at steady state.

6. Homogeneous case. In the first case, the aquifer, confining blanket, and levee materials were assigned identical soil properties.

6.1. Varying only the saturated hydraulic conductivity. The approach used in this research was to start with the simplest case and build on that effort with more complicated scenarios. In this initial run, only saturated hydraulic conductivity was varied with values, $0.001,0.01,0.1,1.0,10.0$, and $100.0 \mathrm{ft} / \mathrm{day}$ $\left(3.528 \times 10^{-7}, 3.528 \times 10^{-6}, 3.528 \times 10^{-5}, 3.528 \times 10^{-4}, 3.528 \times 10^{-3}\right.$, and $3.528 \times 10^{-2} \mathrm{~cm} / \mathrm{sec}$, respectively $)$. The hydraulic conductivity values correspond to the following material types: clay, silt, silty sand, fine sand, and coarse sand, respectively [14]. Table 6.1 gives the values of the other input parameters used for these runs. Figs. 6.1, 6.2, and 6.3 show the times to achieve 25, 50, and $75 \%$ of the respective steady-state values of the pore pressure at the toe of the levee beneath the blanket, the flow rate through the flux section, and the levee saturation coefficient, respectively. The computer runs were terminated after 1000 days, so in the cases where more than 1000 days are needed to achieve the given percentages of steady state, no values are plotted. Observations are as follows:

- The saturated hydraulic conductivity has a significant impact on results.

- For hydraulic conductivity values of $0.001 \mathrm{ft} /$ day and $0.01 \mathrm{ft} /$ day, none of the given percentages of the steady-state values of the pore pressure beneath the blanket at the toe and the flow rate through the flux section can develop within 1000 days.

- The same basic trend occurs in each plot with only the separation among curves varying.

6.2. Varying the saturated hydraulic conductivity and volumetric compressibility. Once it was found that the magnitude of the hydraulic conductivity value had a significant impact on the results of a transient analysis, other parameters were varied in conjunction with the hydraulic conductivity. Here, both $k_{s}$ and $m_{v}$ were varied and results collected for the same times to percentage of steady state as before. $m_{v}$ values of $1.0 \times 10^{-3}, 1.0 \times 10^{-5}$, and $1.0 \times 10^{-7} \mathrm{psf}^{-1}$ were used with the same $k_{s}$ values as before. The results are given in Figs. 6.4, 6.5, and 6.6. It is important to note that all combinations of $k_{s}$ and $m_{v}$ are not what a practicing engineer may choose. However, to maintain continuity of trends, they are kept in the plots. The method of ranges (Eq. 2.7) was applied to these results, and the result of this computation is provided in Table 6.2. For all computations in this paper where Eq. 2.7 is used, $Y_{\max }=1000$. Observations from these results are:

- $m_{v}$ has a significant impact on results but slightly less influence than $k_{s}$.

- Pore pressure, flow rate, and levee saturation coefficient have the same basic trend.

- The greater the hydraulic conductivity, the less time it takes to achieve steady state.

- The greater the volumetric compressibility, the more time it takes to achieve steady state. 


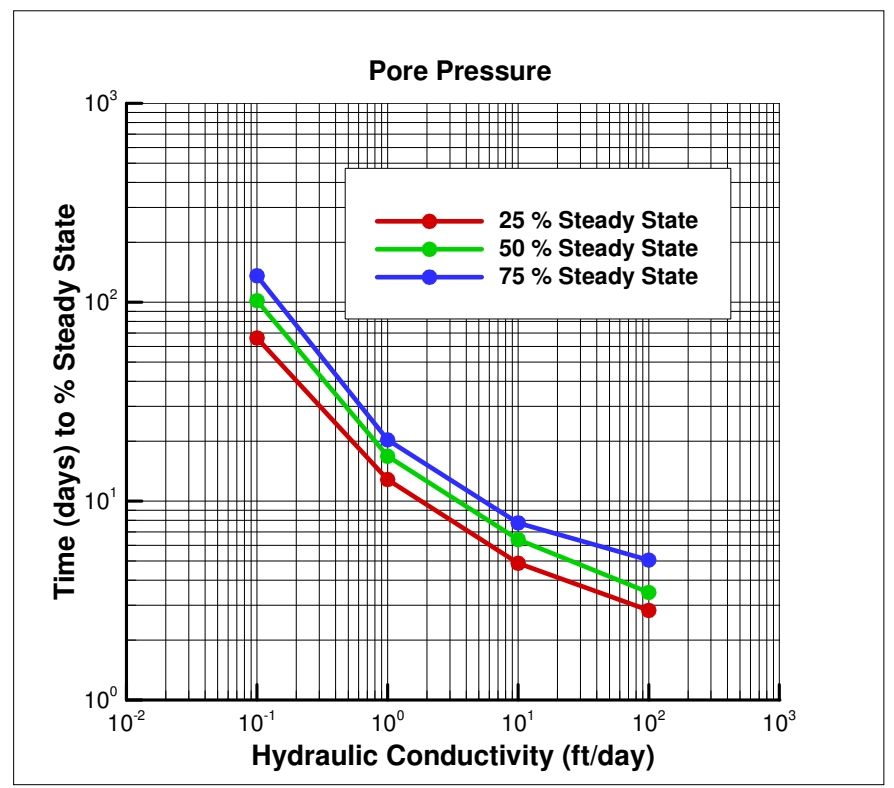

Fig. 6.1: Plot of times to percentage of steady state for pore pressure.

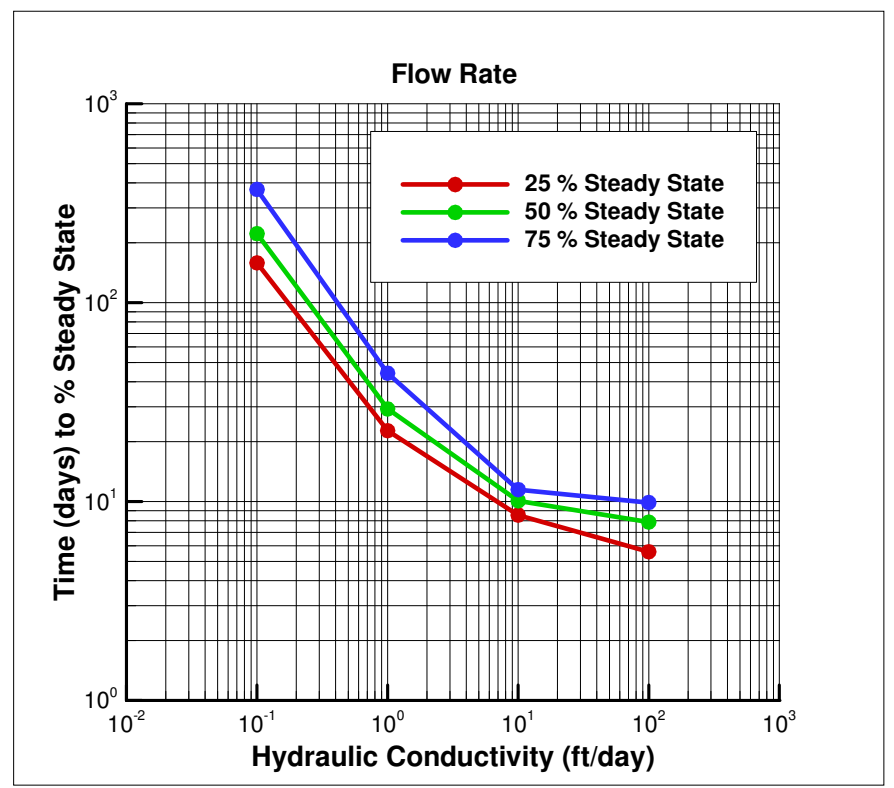

Fig. 6.2: Plot of times to percentage of steady state for flow rate through the flux section.

6.3. Varying all input parameters except volumetric compressibility. The next analysis was performed with all input parameters being varied except $m_{v}$, and $s_{r}$ was computed as before using Eq. 2.7. The values of the parameters used in this analysis are given in Table 6.3 . There are two reasons why only $m_{v}=$ $0.00001 \mathrm{psf}^{-1}$ was used, and they are as follows: (1) When $m_{v}$ was set to $0.001,0.00001$, and $0.0000001 \mathrm{psf}^{-1}$ as before, all the $s_{r}$ values were 0.99 . Thus, no separation of importance was possible. (2) $m_{v}=0.00001 \mathrm{psf}^{-1}$ is often selected by practicing engineers as a default option. Observations are as follows: 


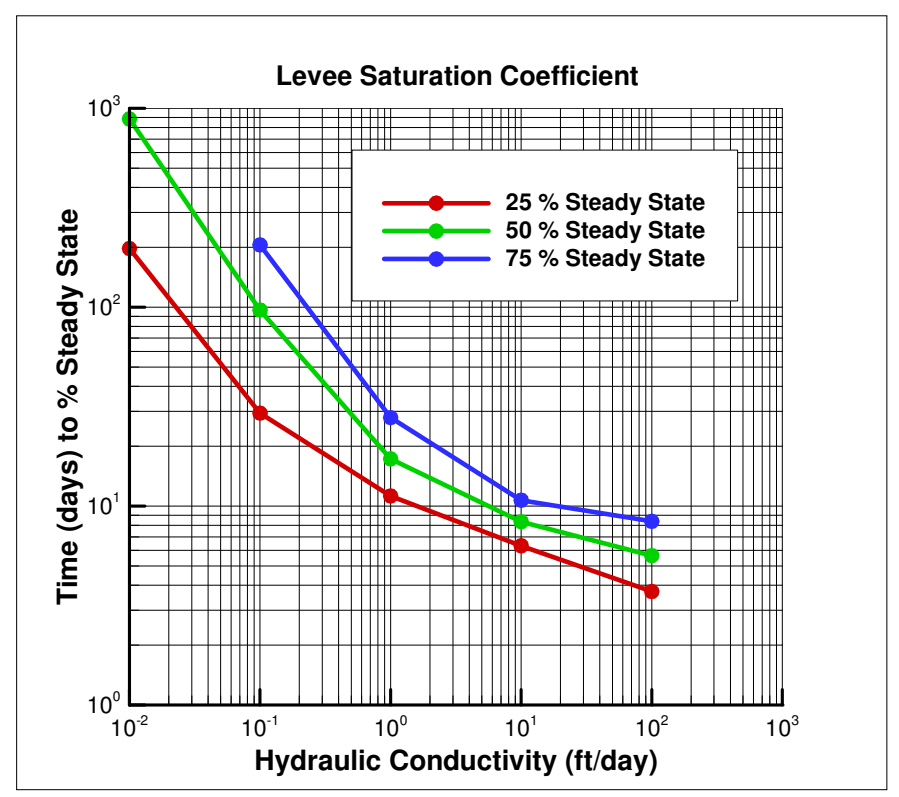

Fig. 6.3: Plot of times to percentage of steady state for levee saturation coefficient.

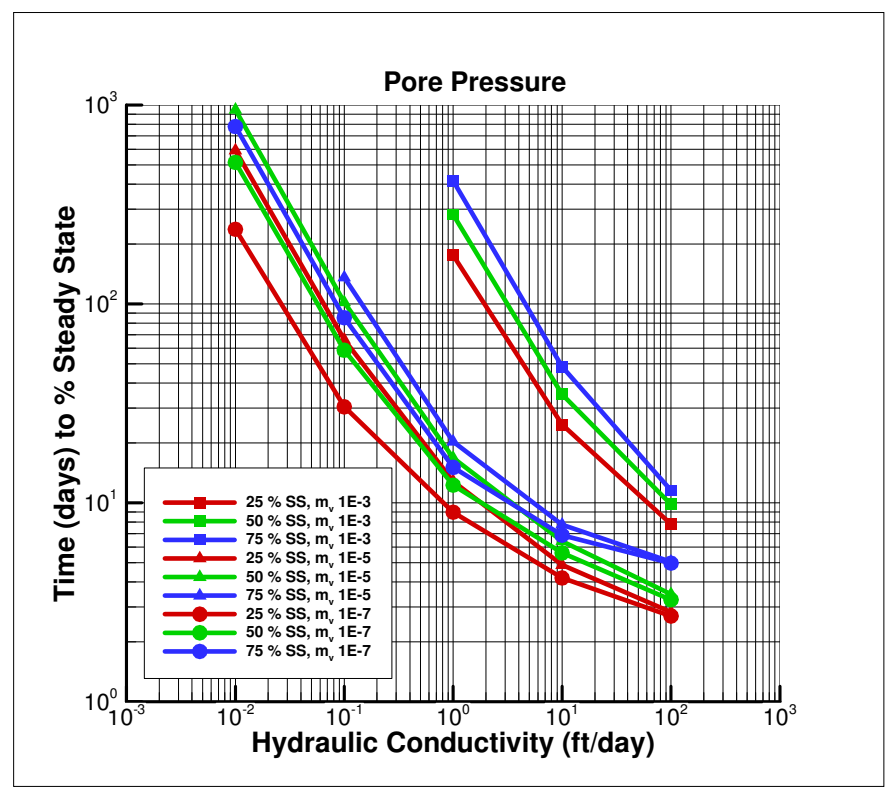

Fig. 6.4: Plot of times to percentage of steady state for pore pressure for $k_{s}$ and $m_{v}$ combinations.

- The saturated hydraulic conductivity was shown to be the most sensitive input variable.

- The other input parameters of $\theta_{r}, \theta_{s}, \alpha$, and $n$ all have significant influence on results.

- $\alpha$ and $n$ are the most sensitive of the unsaturated flow parameters.

7. Heterogeneous Case. A final experiment involved a more realistic scenario in which the three different layers of levee, blanket, and aquifer in Fig. 3.1 were each assigned different material properties. Table 7.1 gives 


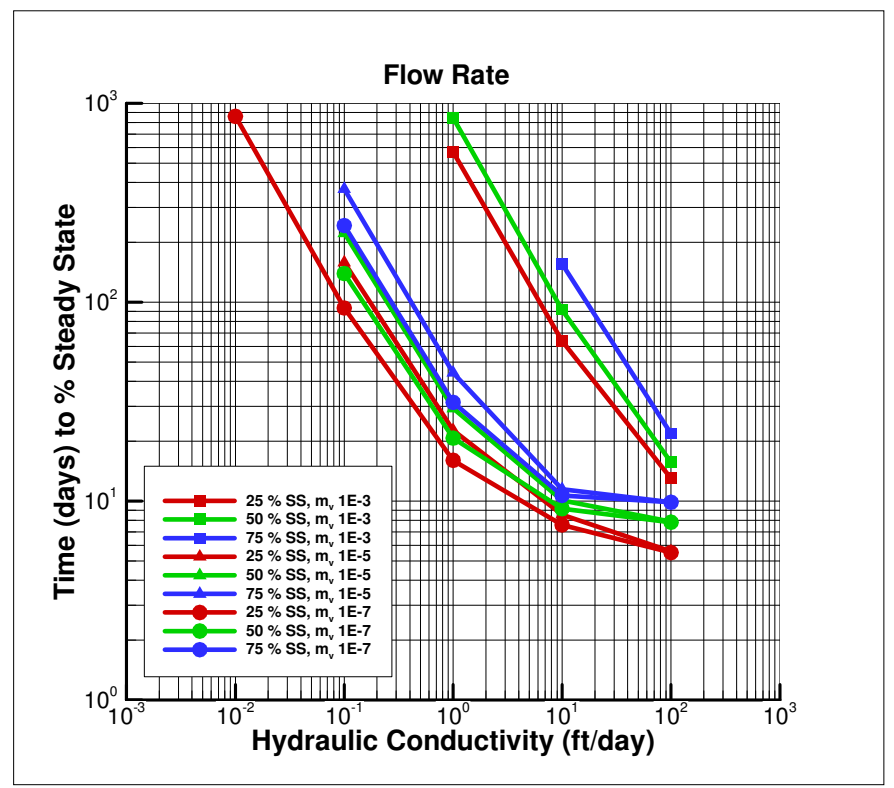

Fig. 6.5: Plot of times to percentage of steady state for flow rate through the flux section for $k_{s}$ and $m_{v}$ combinations.

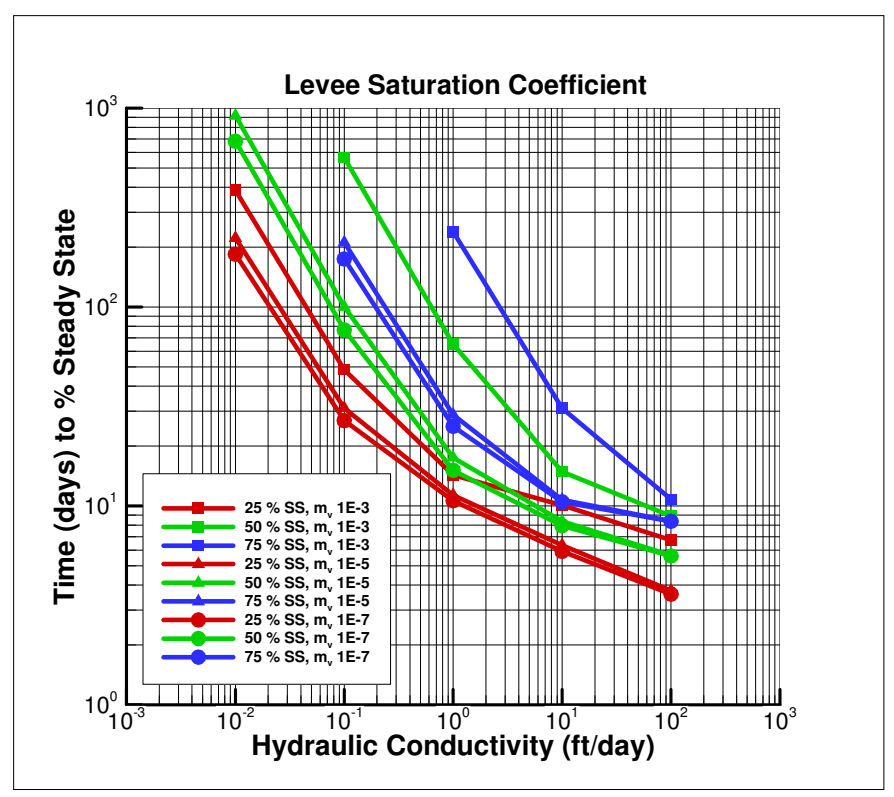

Fig. 6.6: Plot of times to percentage of steady state for levee saturation coefficient for $k_{s}$ and $m_{v}$ combinations.

the variation of soil types in the three layers, and Table 7.2 gives the values of soil properties used. The 14 allowable combinations of saturated hydraulic conductivity for the levee and blanket are given in Table 7.3. Saturated hydraulic conductivity values considered for the aquifer are $k_{s, \text { aquifer }}=10$ and $100 \mathrm{ft} /$ day.

Because $k_{s}, m_{v}, \theta_{r}, \theta_{s}, \alpha$, and $n$ are considered for sensitivity for both the levee and blanket, over one million scenarios would be needed to use the sensitivity method of ranges. Thus, the sensitivity method of 
Table 6.2: Sensitivity coefficient, $s_{r}$, values for $k_{s}$ and $m_{v}$ for the times to different percentages of steady state for pore pressure, flow rate, and levee saturation coefficient.

\begin{tabular}{|c|c|c|c|}
\hline \multicolumn{4}{|c|}{$s_{r}$ for pore pressure } \\
\hline & Percent of steady state \\
\hline Input parameter & 25 & 50 & 75 \\
\hline$k_{s}$ & 0.9973 & 0.9967 & 0.9950 \\
$m_{v}$ & 0.9696 & 0.9415 & 0.9148 \\
\hline \multicolumn{4}{|c|}{ for flow rate } \\
\hline \multicolumn{4}{|c|}{ Percent of steady state } \\
\hline Input parameter & 25 & 50 & 75 \\
\hline$k_{s}$ & 0.9945 & 0.9922 & 0.9901 \\
$m_{v}$ & 0.9065 & 0.8605 & 0.9686 \\
\hline$s_{r}$ for levee saturation coefficient \\
\hline \multicolumn{4}{|c|}{ Percent of steady state } \\
\hline Input parameter & 25 & 50 & 75 \\
\hline$k_{s}$ & 0.9964 & 0.9944 & 0.9916 \\
$m_{v}$ & 0.2010 & 0.4863 & 0.8255 \\
\hline
\end{tabular}

Table 6.3: Range of input parameters.

\begin{tabular}{|c|c|}
\hline Material Property & Range of Values Investigated \\
\hline$k_{s}(\mathrm{ft} / \mathrm{day})$ & $0.001,0.01,0.1,1,10,100$ \\
$m_{v}(1 / \mathrm{psf})$ & $1.0 \times 10^{-5}$ \\
$\theta_{r}$ & $0.05,0.1,0.15$ \\
$\theta_{s}$ & $0.40,0.45,0.5$ \\
$\alpha(1 / \mathrm{ft})$ & $0.2,0.4,0.6$ \\
$n$ & $1.25,1.75,2.25$ \\
\hline
\end{tabular}

Table 6.4: Sensitivity coefficient, $s_{r}$, values for $k_{s}, \theta_{r}, \theta_{s}, \alpha$, and $n$ for the times to different percentages of steady state for pore pressure, flow rate, and levee saturation coefficient.

\begin{tabular}{|c|c|c|c|}
\hline \multicolumn{4}{|c|}{$s_{r}$ for pore pressure } \\
\hline & \multicolumn{3}{|c|}{ Percent of steady state } \\
\hline Input parameter & 25 & 50 & 75 \\
\hline$k_{s}$ & 0.9969 & 0.9969 & 0.9951 \\
\hline$\theta_{r}$ & 0.1459 & 0.1486 & 0.1287 \\
\hline$\theta_{s}$ & 0.1459 & 0.1486 & 0.1287 \\
\hline$\alpha$ & 0.3154 & 0.3048 & 0.2591 \\
\hline$n$ & 0.4503 & 0.4046 & 0.3186 \\
\hline \multicolumn{4}{|c|}{$s_{r}$ for flow rate } \\
\hline & \multicolumn{3}{|c|}{ Percent of steady state } \\
\hline Input parameter & 25 & 50 & 75 \\
\hline$k_{s}$ & 0.9945 & 0.9922 & 0.9901 \\
\hline$\theta_{r}$ & 0.0961 & 0.0672 & 0.1146 \\
\hline$\theta_{s}$ & 0.0961 & 0.0672 & 0.1146 \\
\hline$\alpha$ & 0.1874 & 0.1637 & 0.3257 \\
\hline$n$ & 0.1874 & 0.1767 & 0.3072 \\
\hline \multicolumn{4}{|c|}{$s_{r}$ for levee saturation coefficient } \\
\hline & \multicolumn{3}{|c|}{ Percent of steady state } \\
\hline Input parameter & 25 & 50 & 75 \\
\hline$k_{s}$ & 0.9968 & 0.9957 & 0.9926 \\
\hline$\theta_{r}$ & 0.2585 & 0.2206 & 0.1620 \\
\hline$\theta_{s}$ & 0.2585 & 0.2206 & 0.1620 \\
\hline$\alpha$ & 0.4692 & 0.5659 & 0.2966 \\
\hline$n$ & 0.2263 & 0.3417 & 0.2905 \\
\hline
\end{tabular}


Table 7.1: Description of soils in levee layers.

\begin{tabular}{|c|c|}
\hline Layer & Material variation \\
\hline Levee & Clay to gravelly sand \\
Blanket & Clay to sandy silt \\
Aquifer & Sand to gravelly sand \\
\hline
\end{tabular}

Table 7.2: Soil property data for selected soils.

\begin{tabular}{|c|c|c|c|c|c|c|}
\hline Soil classification & $k_{s}(\mathrm{ft} / \mathrm{day})$ & $\theta_{r}$ & $\theta_{s}$ & $\alpha(1 / \mathrm{ft})$ & $n$ & $m_{v}(1 / \mathrm{psf})$ \\
\hline Clay & 0.001 & 0.05 & 0.50 & $0.076,0.137$ & 1.05 & $5 \times 10^{-5}$ \\
Lean clay & 0.01 & 0.045 & 0.45 & $0.152,0.228$ & $1.1,1.15$ & $1 \times 10^{-5}$ \\
Silt & 0.1 & 0.04 & 0.40 & $0.243,0.610$ & $1.2,1.35$ & $5 \times 10^{-6}$ \\
Silty sand/sandy silt & 1 & 0.035 & 0.35 & $0.762,1.829$ & $1.4,1.6$ & $1 \times 10^{-6}$ \\
Sand & 10 & 0.03 & 0.30 & $2.286,4.420$ & $1.9,2.7$ & $5 \times 10^{-7}$ \\
Gravelly sand & 100 & \multicolumn{5}{|c}{ Not used } \\
\hline
\end{tabular}

Table 7.3: Hydraulic conductivity (ft/day) combinations for levee, blanket, and aquifer layers. The check marks indicate the allowable combinations.

\begin{tabular}{|c|c|c|c|c|c|}
\hline$k_{s, \text { blanket }}$ & \multicolumn{5}{|c|}{$k_{s, \text { levee }}$} \\
\hline & 0.001 & 0.01 & 0.1 & 1 & 10 \\
\hline 0.001 & $\sqrt{ }$ & $\sqrt{ }$ & $\sqrt{ }$ & & \\
\hline $\begin{array}{c}0.01 \\
0.1\end{array}$ & $\sqrt{ }$ & $\sqrt{ }$ & $\sqrt{ }$ & $\sqrt{ }$ & $\gamma$ \\
\hline 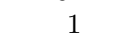 & & & $\sqrt{ }$ & $\sqrt{ }$ & $\checkmark$ \\
\hline
\end{tabular}

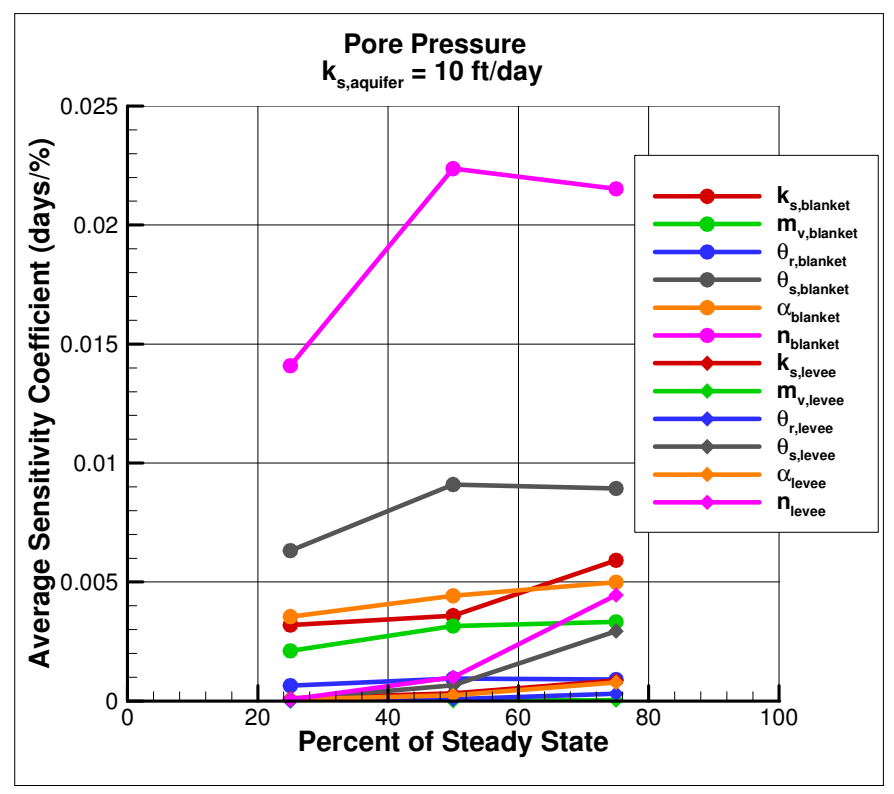

Fig. 7.1: Plot of average $s_{m}$ for pore pressure for $k_{s, a q u i f e r}=10 \mathrm{ft} /$ day.

slopes given by Eq. 2.3 was used. Another disadvantage of the method of ranges approach used thus far is that some combinations of the input parameters would not be used by practicing engineers. Thus, the material property data were restricted to the allowable combinations given in Table 7.3 and values given in Table 7.2. 


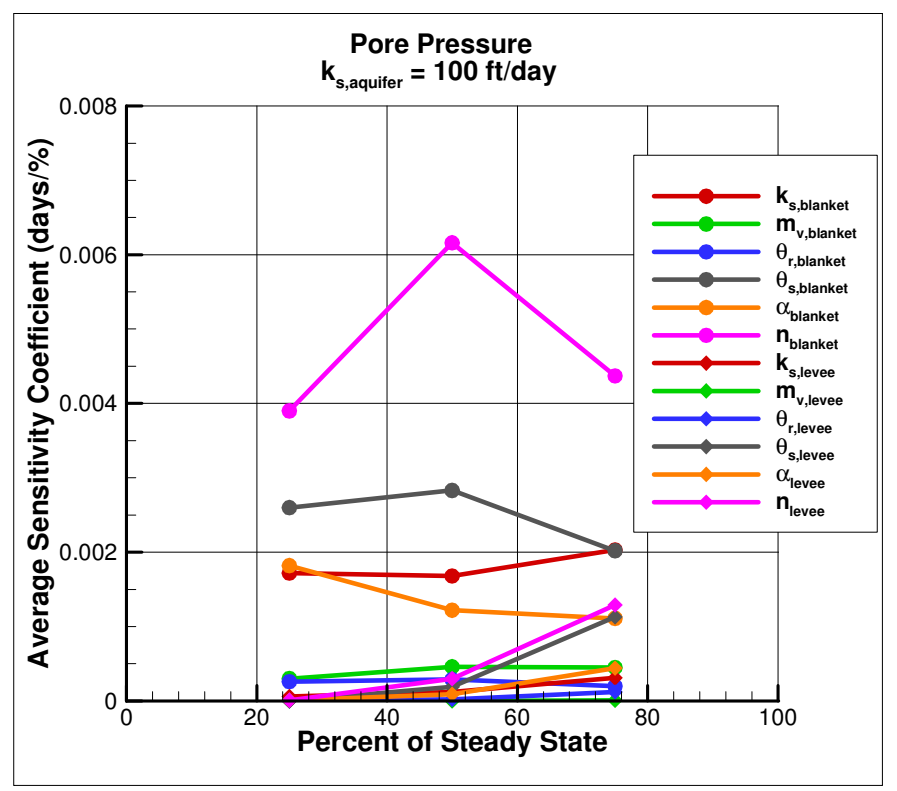

Fig. 7.2: Plot of average $s_{m}$ for pore pressure for $k_{s, \text { aquifer }}=100 \mathrm{ft} /$ day.

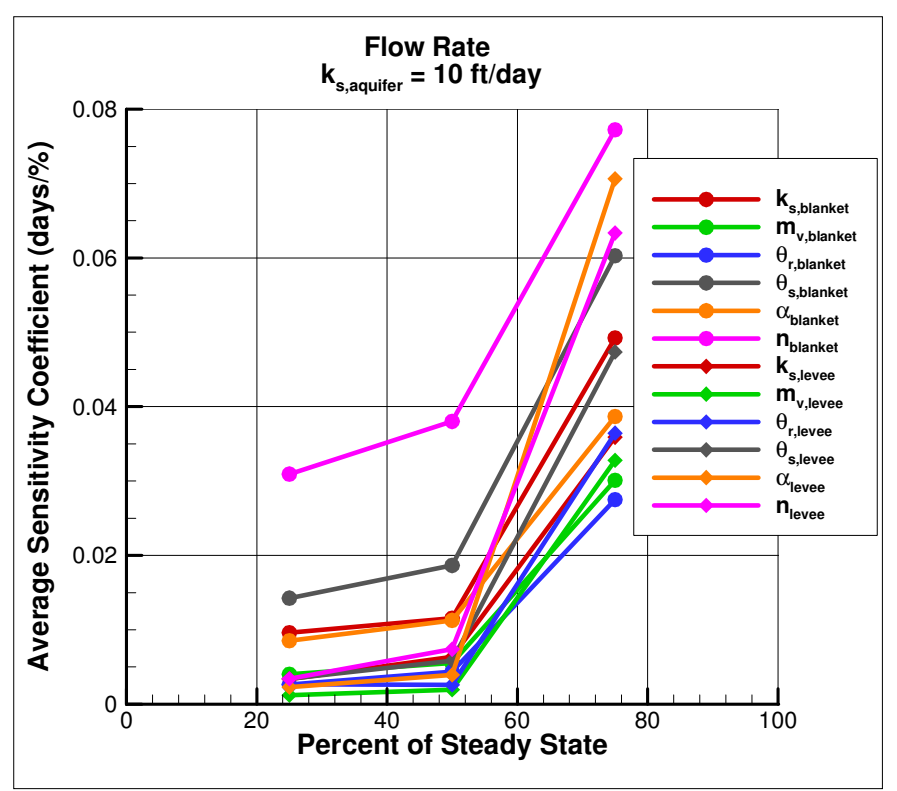

Fig. 7.3: Plot of average $s_{m}$ for flow rate for $k_{s, \text { aquifer }}=10 \mathrm{ft} / \mathrm{day}$.

When Eq. 2.3 was used in the sensitivity analysis, the allowable combinations described above were all considered. For a given scenario, the six soil parameters, $k_{s}, m_{v}, \theta_{r}, \theta_{s}, \alpha$, and $n$, for both the levee and blanket (12 parameters) were varied slightly in succession, leaving all the other input parameters constant when a given parameter was varied. This required that for each valid set of soil values or scenario, 13 simulations were needed (the original run plus 12 variations). Two separate parallel high performance computing runs were made, one 


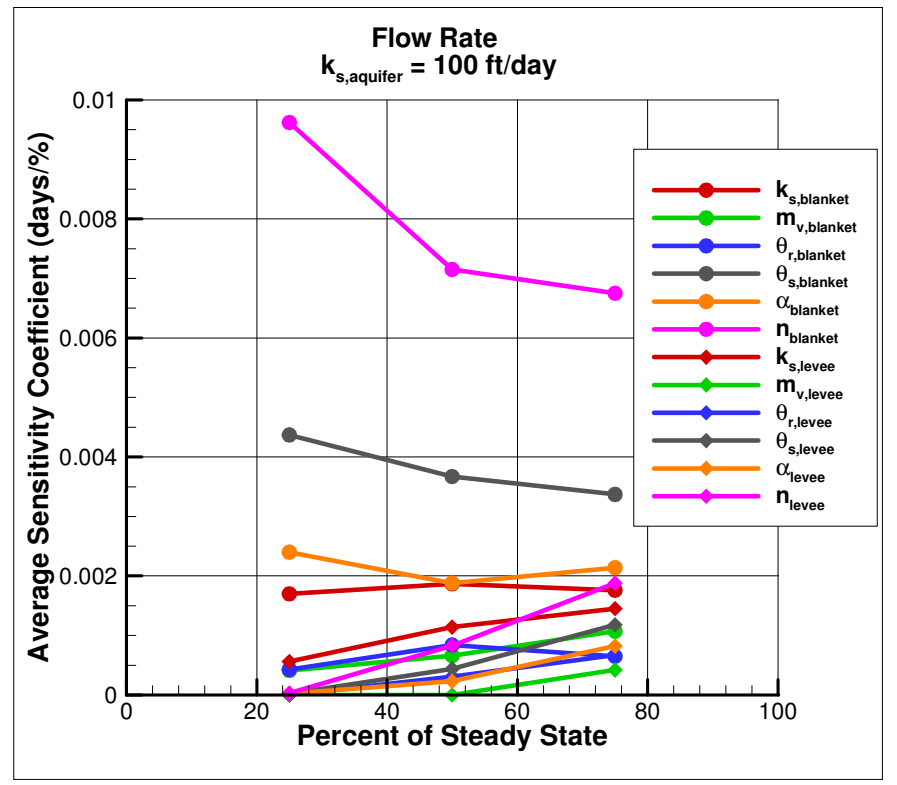

Fig. 7.4: Plot of average $s_{m}$ for flow rate for $k_{s, a q u i f e r}=100 \mathrm{ft} /$ day.

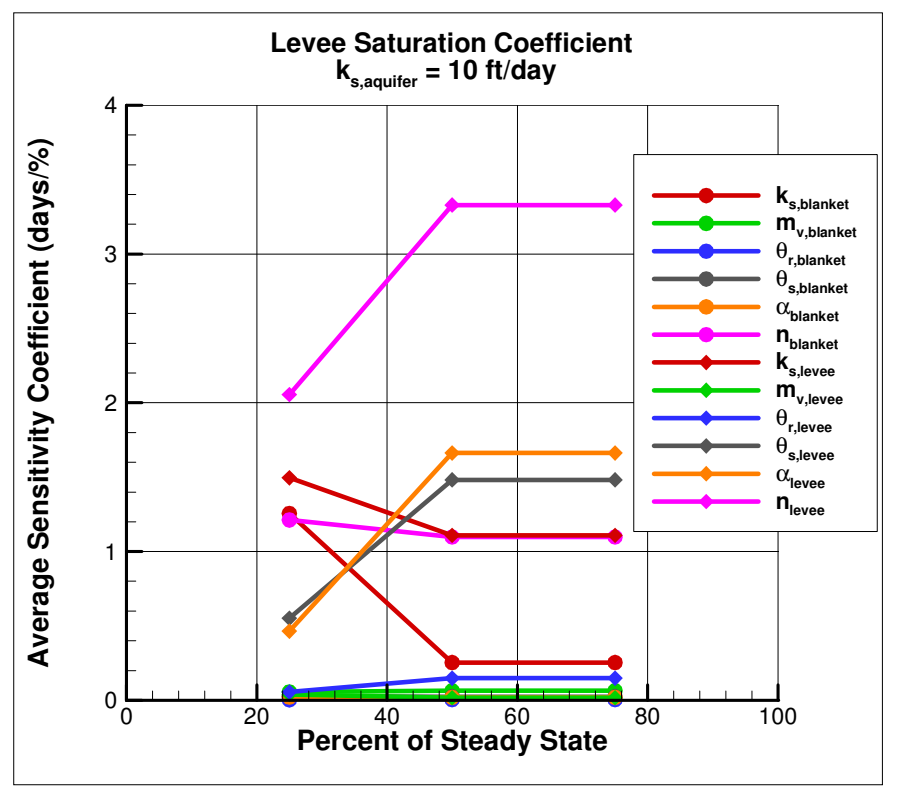

Fig. 7.5: Plot of average $s_{m}$ for levee saturation coefficient for $k_{s, \text { aquifer }}=10 \mathrm{ft} /$ day.

with $k_{s, \text { aquifer }}=10 \mathrm{ft} /$ day, and another with $k_{s, \text { aquifer }}=100 \mathrm{ft} /$ day. Thus, two sets of 2444 simulations each were needed. All 2444 simulations for a given $k_{s, \text { aquifer }}$ value were accomplished with a parallel MPI job using 2444 processes and taking approximately 1.5 hours.

The sensitivity coefficient, $s_{m}$, from Eq. 2.3 was computed for all the valid combinations for time to achieve 25,50 , and $75 \%$ of the respective steady-state value of pore pressure, flow rate, and levee saturation coefficient, 


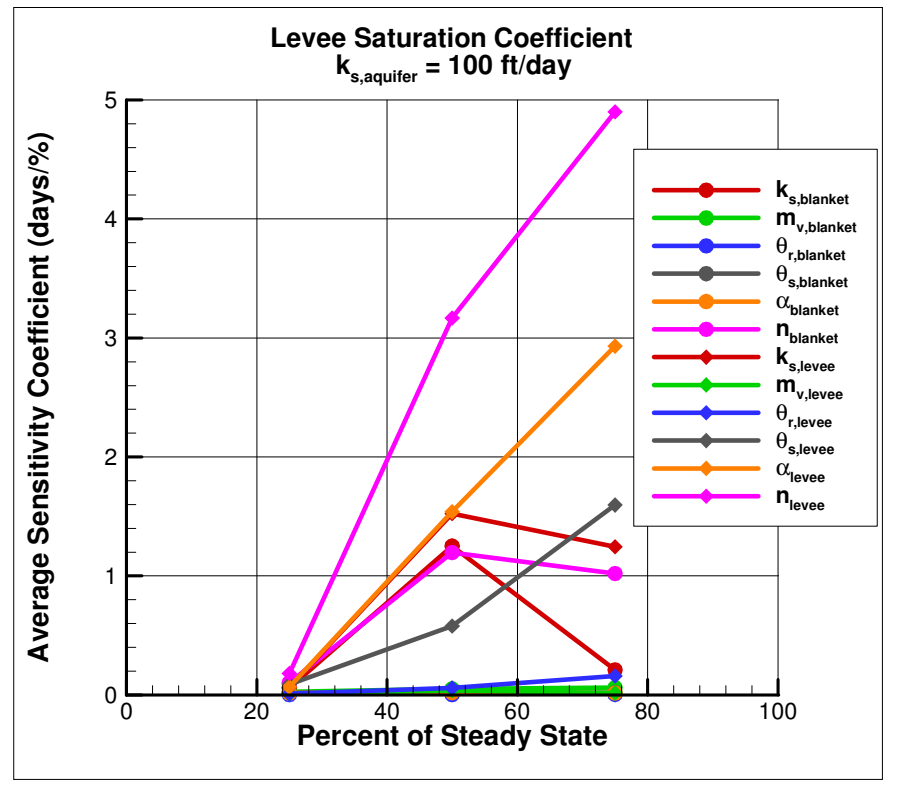

Fig. 7.6: Plot of average $s_{m}$ for levee saturation coefficient for $k_{s, \text { aquifer }}=100 \mathrm{ft} /$ day.

and the average value of $s_{m}$ over these valid combinations for each input parameter was tabulated. Both runs for $k_{s, \text { aquifer }}=10$ and $100 \mathrm{ft} /$ day were done, and the results are given in Figs. 7.1, 7.2, 7.3, 7.4, 7.5, and 7.6. Observations are as follows:

- Pore pressure at the toe of the levee and flow rate are 2-3 orders of magnitude less sensitive to the input parameters than is the levee saturation coefficient.

- The input parameters for both the blanket and the levee are important.

- The second van Genuchten unsaturated flow parameter, $n$, is the most sensitive input variable for most of the scenarios analyzed.

- The sensitivity coefficients for pore pressure and flow rate are approximately an order of magnitude less when $k_{\text {s,aquifer }}=100 \mathrm{ft} /$ day as compared to $k_{s, \text { aquifer }}=10 \mathrm{ft} /$ day.

8. Conclusions. This sensitivity study considered a large number of scenarios and was made feasible only through the use of high performance, parallel computers. This is especially true because the scenarios can be run independently without any communication among MPI processes. The results of the study indicate the need to obtain all the input parameters (saturated hydraulic conductivity, volumetric compressibility, residual moisture content, saturated moisture content, and the two van Genuchten parameters) as accurately as possible since the output quantities of interest show a significant sensitivity to each parameter for at least some of the scenarios analyzed. The volumetric compressibility had a dominant effect on output values in the homogeneous case but ranked near the bottom of the list in the case where all three layers had different material properties. The second van Genuchten parameter ranked low in sensitivity in the homogeneous case for pore pressure and flow rate but ranked very high when all three layers had different material properties. When all three layers had different material properties, the van Genuchten unsaturated flow parameters for the blanket often dominated for pore pressure and flow rate, whereas the unsaturated flow parameters for the levee dominated for levee saturation coefficient.

Many of the sensitivity analyses assume that the relationship between input parameters and output variables is linear. The application of unsaturated transient flow is highly nonlinear, so these analyses are of limited value. The method of slopes is suitable for a nonlinear application, but it is very compute-intensive. However, with high performance, parallel computing, this obstacle can be easily overcome since the computation involved for different scenarios is an embarrassingly parallel task. A disadvantage of the method of slopes is that it gives 
a local value that varies greatly over the different scenarios. A simple average of the results over the different scenarios as presented here could be improved with a more sophisticated analysis. This is a topic of future research.

The method of ranges is acceptable for the application presented in this paper, but it has the disadvantage that many scenarios are needed to explore a full range of input parameters and thus to obtain comprehensive results. However, the number of combinations of input parameters can be reduced by limiting the scenarios to only those of interest to practicing engineers.

\section{REFERENCES}

[1] F. T. TraCy, User's guide for a plane and axisymmetric finite element program for steady state seepage problems, Instruction Report IR K-83-4, U.S. Army Engineer Research and Development Center, Vicksburg, MS, 1983.

[2] N. L. JonEs, SEEP2D primer, GMS documentation, Environmental Modeling Research Laboratory, Brigham Young University, Provo, Utah, 1999.

[3] GMS, Groundwater Modeling System, commercial version, www.aquaveo.com/GMS, 2016.

[4] GMS, Groundwater Modeling System, government version, http://chl.erdc.usace.army.mil/gms, 2016.

[5] Geo-Slope, Seepage modeling with SEEP/W, Calgary, Alberta, Canada, 2012.

[6] D. M. Hamby, A review of techniques for parameter sensitivity analysis of environmental models, Environmental Monitoring and Assessment, 32 (1994), pp. 135-154.

[7] R. W. Atherton, R. B. Schainker, ANd E. R. Ducot, On the statistical sensitivity analysis of models for chemical kinetics, AIChE, 21 (1975), pp. 441-448.

[8] S. MenL, Use of Picard and Newton iteration for solving nonlinear ground water flow equations, Ground Water, 44 (2006), pp. 583-594.

[9] F. O. Hoffman and R. H. Gardner, Evaluation of uncertainties in environmental radiological assessment models, In: J. E. Till and H. R. Meyer (eds.), Radiological Assessments: a Textbook on Environmental Dose Assessment, Report No. NUREG/CR-3332, U.S. Nuclear Regulatory Commission, Washington, DC, 1983.

[10] R. H. Gardner, R. V. O'Neill, J. B. Mankin, and J. H. Carney, A comparison of sensitivity analysis and error analysis based on a stream ecosystem model, Ecol. Modelling, 12 (1981), pp. 173-190.

[11] W. J. Conover, Practical Nonparametric Statistics, 2nd edition, Oxford University Press, John Wiley \& Sons, New York, 1980.

[12] International Atomic Energy Agency (IAEA), Evaluating the reliability of predictions made using environmental transfer models, Safety Series No. 100, Report No. STI/PUB/835, Vienna, Austria, pp. 1-106, 1989.

[13] F. T. Tracy, T. L. Brandon, and M. K. Corcoran, Transient seepage analyses in levee engineering practice, In review, U.S. Army Engineer Research and Development Center, Vicksburg, MS, 2016.

[14] K. Terzaghi, B. Peck, and G. Mesr, Soil Mechanics in Engineering Practice, John Wiley \& Sons, New York, 1996.

Edited by: Dana Petcu

Received: Dec 18, 2015

Accepted: Mar 8, 2016 